\title{
Interfacial Segregation, Pore Formation and Scale Adhesion on NiAl Alloys
}

\author{
P. Y. Hou ${ }^{1}$ and K. Priimak ${ }^{1,2}$ \\ ${ }^{1}$ Lawrence Berkeley National Laboratory \\ Materials Sciences Division \\ Berkeley, CA 94720 \\ ${ }^{2}$ University of California, Berkeley, CA 94720
}

\begin{abstract}
$\mathrm{Ni}-40$ and $50 \mathrm{at} \% \mathrm{Al}$ alloys were oxidized at $1000^{\circ} \mathrm{C}$ for various times in oxygen. Auger electron microscopy was used to study the interface chemistry after scale spallation in ultra high vacuum. The interfacial failure stresses were determined using a tensile pull tester and related to the interface chemistry, pore area and density. Results showed that sulfur started to segregate to areas of the $\mathrm{Al}_{2} \mathrm{O}_{3} / \mathrm{Ni40Al}$ interface where the scale was in contact with the alloy after a complete layer of $\alpha-\mathrm{Al}_{2} \mathrm{O}_{3}$ developed there; the concentration then gradually increased to a steady level of $\sim 2$ at $\%$. However, sulfur did not segregate to similar areas of the $\mathrm{Al}_{2} \mathrm{O}_{3} / \mathrm{Ni} 50 \mathrm{Al}$ interface even after extended oxidation when it was amply present on interfacial void faces. This behavior demonstrated a strong dependence of interface segregation on $\mathrm{NiAl}$ alloy composition. Interfacial failure stress was found to decrease with increasing sulfur content between voids and with higher interface porosity. The level of porosity was strongly related to the sulfur content in the alloy. When Ni40Al was doped with excess sulfur, the segregation behavior did not change, but the interfacial pore density increased significantly. The detrimental effect of sulfur on scale adhesion is two-fold: to weaken the interface and to enhance interfacial pore formation.
\end{abstract}

KEY WORDS: $\mathrm{NiAl}, \mathrm{Al}_{2} \mathrm{O}_{3}$, oxide/metal interface, segregation, sulfur, adhesion, interface void.

\section{INTRODUCTION}

The segregation of indigenous sulfur impurity from an alloy to the $\mathrm{Al}_{2} \mathrm{O}_{3}$ scale/alloy interface during high temperature oxidation is often considered the major cause that weakens the interface [1-4]. Systematic studies of the chemical changes at $\mathrm{Al}_{2} \mathrm{O}_{3}$ /alloy interfaces as a function of oxidation time have in recent years been carried out for $\mathrm{FeCrAl}$ [5], $\mathrm{Fe}_{3} \mathrm{Al}$ and $\mathrm{FeAl}[6,7]$, where the alloys normally contain about $20 \mathrm{ppm}$ of sulfur. Although sulfur was found to be the major segregant at these scale/alloy interfaces, the segregation behavior, in terms of rate and amount, varied significantly with different alloys and differed from surface segregation. For example, at the $\mathrm{Al}_{2} \mathrm{O}_{3} / \mathrm{FeCrAl}$ interface, cosegregation of $\mathrm{Cr}$ with $\mathrm{S}$ took place, which gave rise to greater than one monolayer of $\mathrm{S}$. The amount saturated as early as 12 minutes at $1000^{\circ} \mathrm{C}$, where the rate was determined by $\mathrm{S}$ diffusion in the alloy $[5,7,8]$. For the iron aluminides, $\mathrm{S}$ was the sole segregant at these scale/alloy interfaces, but its steady state level was slowly reached only after a complete $\alpha$ - 
$\mathrm{Al}_{2} \mathrm{O}_{3}$ layer formed at the interface [6-8]. On a Fe-40at\% $\mathrm{Al}$ alloy, this behavior has been shown with conventional as well as field emission Auger electron microscopy [9]. The amount saturated at the intact $\mathrm{Al}_{2} \mathrm{O}_{3}$ /alloy interface was about 0.5 monolayer, but cosegregation of $\mathrm{Al}$ and $\mathrm{S}$ took place on surfaces of voids that were present at the interface. Whether the same kind of segregation behavior found on $\mathrm{FeAl}$ can be expected for $\mathrm{NiAl}$ is unknown.

The oxidation behavior of NiAl has been studied extensively [10-18]. The firstformed oxide is $\theta$ or $\gamma-\mathrm{Al}_{2} \mathrm{O}_{3}$ that grows mainly by cation outward transport $[11,15]$. $\alpha-$ $\mathrm{Al}_{2} \mathrm{O}_{3}$ later nucleates at the scale/alloy interface [17] and the initially formed alumina transforms to the more stable $\alpha$ form with time. The $\alpha-\mathrm{Al}_{2} \mathrm{O}_{3}$ grows by both aluminum outward and oxygen inward transport, with the latter being more dominant $[13,15]$. Because of this phase transformation, the oxidation kinetics show two parabolic stages separated by a gradual transition. At $1000^{\circ} \mathrm{C}$, the rate constant for the initial stage is about $10^{-12} \mathrm{~g}^{2} / \mathrm{cm}^{4} \mathrm{~s}$, and it is more than two orders of magnitude faster than the later steady state [12]. Interfacial voids that are several times larger in diameter than the oxide grain sizes are often observed on the alloy surface [10,18-20]. These voids deepen into the alloy with facetted faces and distinct shapes that are associated with the alloy grains. Similar pore formation has been observed on $\mathrm{FeAl}$ alloys [21,22]. It was found that most voids nucleated during the initial stage of oxidation [21], where the scale grows predominantly by cation outward transport. Sulfur in the alloy has been suggested to enhance pore formation by lowering its surface energy [23]. Surface impurities can also have the same effect [24].

Despite these prior studies on $\mathrm{NiAl}$, the chemistry of the $\mathrm{Al}_{2} \mathrm{O}_{3} / \mathrm{NiAl}$ interface and how it changes with oxidation time have not been systematically examined. The purpose of this work is to study the chemical changes at $\mathrm{Al}_{2} \mathrm{O}_{3} / \mathrm{NiAl}$ interfaces as oxidation proceeds, and relates that to the interface morphology and the interfacial strength. The amounts of segregants on interfacial voids (free surface) and on areas where the scale was in contact with the alloy before analysis (interface) are determined separately to compare their segregation behaviors. Preliminary results have been published in a paper [25] that concentrates on the details of the segregation behavior. This paper focuses on the difference between the two compositions of NiAl: Ni-50 and 40 at $\% \mathrm{Al}$ (both with the $\beta$ $\mathrm{NiAl}$ structure), and illustrates the relationships between sulfur segregation, interface pore density and interface strength.

\section{EXPERIMENTAL METHODS}

Different $\mathrm{Ni}-50 \mathrm{at} \% \mathrm{Al}(\mathrm{NiAl})$ and $\mathrm{Ni}-40$ at\%Al alloys were used in this study, all of them made with high purity starting materials. Their compositions and some impurity contents are given in Table 1. Three batches of Ni50Al, identified as NiAl (1-3), and one

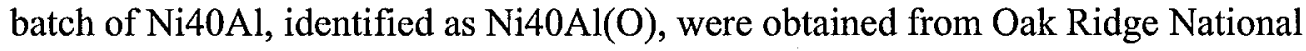
Laboratory. They were prepared by induction melting, followed by annealing at $1300^{\circ} \mathrm{C}$ for 4 hours. The labels (1)-(3) used to identify the Ni50Al alloys are based on their slightly different $\mathrm{S}$ and $\mathrm{C}$ contents, where (1) has the lowest levels of both. The purer alloy also 


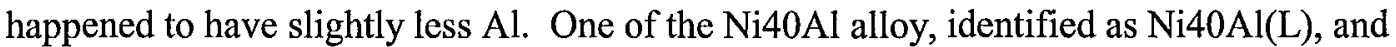
the S-doped Ni40Al were made at Lawrence Berkeley National Laboratory by arc melting, followed by annealing at $1150^{\circ} \mathrm{C}$ for 15 hours. All the normal purity alloys contain small amounts of sulfur impurity, about 2-6 ppma. The S-doped alloy was made by co-melting $\mathrm{Al}$ and Ni with NiS powders, and it contains more than $30 \mathrm{ppm}$ of sulfur. The oxidation and segregation behaviors are often similar between the three batches of $\mathrm{Ni} 50 \mathrm{Al}$ and the two batches of $\mathrm{Ni} 40 \mathrm{Al}$, so unless otherwise noted, the results presented here do not make distinctions between the different batches.

Specimen discs about $1-2 \mathrm{~cm}$ in diameter and $1 \mathrm{~mm}$ thick were cut from the ingot. All sides of the specimens were grounded using $\mathrm{SiC}$ paper with one main face polished to a $1 \mu \mathrm{m}$ surface finish using diamond paste, and the specimen was cleaned ultrasonically in acetone before oxidation in flowing, dry oxygen. Most oxidation tests were performed at $1000^{\circ} \mathrm{C}$, with a few at $1150^{\circ} \mathrm{C}$, in a horizontal furnace, where the specimen was placed in an alumina boat with a thermocouple at its back. The assembly was inserted slowly into the hot zone. The specimen surface temperature reached $1000^{\circ} \mathrm{C}$ in about 10 minutes. After the desired oxidation time, which varied from $10 \mathrm{~min}$ to 265 hours, the boat and specimen were quickly pulled out of the furnace and cooled in ambient air. A Cahn TGA system, with a heating rate of $85^{\circ} \mathrm{C} / \mathrm{min}$, was used for thermogravemetic analysis at $1000^{\circ} \mathrm{C}$; both faces of these specimens were polished to a $1 \mu \mathrm{m}$ finish.

Structure of the scale was studied using X-ray diffraction and the morphology examined using scanning electron microscopy (SEM). Chemistry of the scale/alloy interface was studied using Auger electron spectroscopy (AES) after the scale was removed in the ultra high vacuum (UHV) chamber of the AES by the forces of a scratch made on the specimen surface [26]. This technique caused spalling of the scale adjacent to the scratch, exposing areas of the underlying alloy surface that can be examined using a $0.5-1 \mu \mathrm{m}$ size Auger probe. The underside of the oxide was also studied on scale pieces that flipped over during the spalling process, so both sides of the interface, although from different locations, can be examined. Images from secondary electrons were used to distinguish features at the alloy surfaces. These usually include smooth facetted void faces or rough $\mathrm{Al}_{2} \mathrm{O}_{3}$ imprinted interface areas. Several different areas covering more than one alloy grains were examined. Surveys were performed on many similar features in order to obtain a statistical analysis of the results.

The strength of the scale/alloy interface was determined using a Quad Group Sebastian 5 tensile-tester, where a $3 \mathrm{~mm}$ diameter stud with a thin film of adhesive was bonded onto the oxidized surface. The stud was then pulled at an inverted position (Fig. 1a) with a constant loading rate until failure occurs, which was always abrupt. If failure took place at the scale/alloy interface, an example is shown in Fig. 1b, and if more than $75 \%$ of the interfacial area was exposed, the data was considered useful and the interface strength was determined by dividing the failure load over the entire stud area. The adhesive was cured at $150^{\circ} \mathrm{C}$ for $1 \mathrm{hr}$ and has a maximum strength of $103 \mathrm{MPa}$. Three or four studs were tested on each specimen, and every failed area was subsequently examined under the SEM. 
Quantification of interfacial pores was made by analyzing SEM micrographs of the exposed alloy surface. Images magnified 2000 times were randomly taken within the pulled areas, covering several different alloy grains. Only pores greater than the imprints made by $\alpha-\mathrm{Al}_{2} \mathrm{O}_{3}$ oxide grains can be unambiguously identified. Therefore, pores that were counted had a minimum diameter of about $0.5 \mu \mathrm{m}$. Analysis was done using Image Pro Plus software, either by manually defining the perimeter of a pore to get the pore face area that lays at the scale/alloy interface, or a simple count of the number of pores.

\section{RESULTS}

Specimen weight gain as a function of time was examined for all the alloys at $1000^{\circ} \mathrm{C}$ up to 50 hours. All results showed a fast initial stage followed by a slower steady state; the rates of both stages obeyed parabolic kinetics and the rate constants for the two stages are in the range of (2-6) $\times 10^{-12}$ and (2-5) $\times 10^{-14} \mathrm{~g}^{2} / \mathrm{cm}^{4} \mathrm{~s}$ respectively. These numbers agree well with those reported by others for $\mathrm{NiAl}$ [14]. XRD studies indicated that the early stage scales on both $\mathrm{Ni} 50 \mathrm{Al}$ and $\mathrm{Ni40Al}$ were $\theta-\mathrm{Al}_{2} \mathrm{O}_{3} ; \alpha-\mathrm{Al}_{2} \mathrm{O}_{3}$ developed later and it nucleated at the scale/alloy interface. Typical oxide morphology after a layer of $\alpha-\mathrm{Al}_{2} \mathrm{O}_{3}$ formed at the interface is shown in Fig. 2. Under the current oxidation condition, this $\mathrm{Al}_{2} \mathrm{O}_{3}$ phase transformation process barely started at $5 \mathrm{hrs}$ on the $\mathrm{Ni} 50 \mathrm{Al}$, but the entire $\mathrm{Ni40Al}$ interface was covered with $\alpha-\mathrm{Al}_{2} \mathrm{O}_{3}$ by $3 \mathrm{hrs}$, indicating slower transformation on alloys with higher $\mathrm{Al}$ contents. After scale removal, $\alpha-\mathrm{Al}_{2} \mathrm{O}_{3}$ grain imprints are clearly seen on the alloy side of the interface; an example is given in Fig. 3(b). Prior to the development of this $\alpha-\mathrm{Al}_{2} \mathrm{O}_{3}$ layer at the interface, the alloy was in contact with finedgrained $\theta-\mathrm{Al}_{2} \mathrm{O}_{3}$, and this morphology is shown in Fig. 3(a).

Large and easily distinguishable voids were often found on the alloy surface after scale removal (Figs. 3a and 4). As with FeAl [21], they developed early, were highly facetted with their shapes dictated by the alloy grain orientation, grew in size and coalescenced with oxidation time. The number density was significantly lower on Ni50Al (averaging less than $0.3 \times 10^{-2} / \mu \mathrm{m}^{2}$ ) than $\mathrm{Ni40Al}\left(>1 \times 10^{-2} / \mu \mathrm{m}^{2}\right.$ ), but the pore sizes on both alloys were similar for a given oxidation time. Addition of sulfur to the Ni40Al alloy resulted in a much greater density of voids at the interface; a comparison is shown in Fig. 4. Number density as high as $0.1 / \mu \mathrm{m}^{2}$ was found on the specimen oxidized for only 30 minutes.

No impurities were detected on the oxide side of the interface; only $\mathrm{O}$ and $\mathrm{Al}$ were observed. All impurities, if present at the interface, remained on the alloy side after scale removal in UHV. The chemistry found on void faces served as a direct comparison of segregation behaviors between free surfaces and oxide/alloy interfaces. Figure 5 summarizes the change of sulfur content on interfaces and void surfaces on Ni-40 and 50Al. Most oxidations were performed at $1000^{\circ} \mathrm{C}$. A few were carried out at $1150^{\circ} \mathrm{C}(3$ and $100 \mathrm{hrs}$ ) and each one was plotted against an 'equivalent time' at $1000^{\circ} \mathrm{C}$. This is the time necessary to produce the same scale thickness as that at $1150^{\circ} \mathrm{C}$, and it was 
determined using the oxidation rates of the two temperatures, assuming the scale to be fully dense $\alpha-\mathrm{Al}_{2} \mathrm{O}_{3}$.

The most surprising result from Fig. 5 is that $S$ segregated to the interfaces of $\mathrm{Al}_{2} \mathrm{O}_{3} / \mathrm{Ni} 40 \mathrm{Al}$, but not to $\mathrm{Al}_{2} \mathrm{O}_{3} / \mathrm{Ni50Al}$. The latter sometimes contain small amounts of $\mathrm{B}$ and/or $\mathrm{P}[25,8]$, but $\mathrm{S}$ was never detected. A typical AES spectrum from this $\mathrm{S}$-free interface is shown in Fig 6(c). On the Ni40Al, sulfur was the only impurity found; an example is given in Fig. 6b. Similar to Fe40Al [9], S only segregated to the interface after a complete $\alpha-\mathrm{Al}_{2} \mathrm{O}_{3}$ layer developed there, which at $1000^{\circ} \mathrm{C}$ was about 3 hrs. Its subsequent buildup at the interface was gradual, reaching a stead-state level after longer oxidation times to 2 at $\%$, which is equivalent to about 0.2 monolayer. The two batches of $\mathrm{Ni40Al}$, made at ORNL or LBNL, behaved similarly. At the higher temperature of $1150^{\circ} \mathrm{C}$, the amount of $\mathrm{S}$ at the interface was comparable to that found at $1000^{\circ} \mathrm{C}$. Interface composition for the S-doped samples is absent from Fig. 5 due to the presence of numerous tiny voids on the S-doped Ni40Al. These voids are much smaller than the Auger probe size, and they were not resolvable under the SEM of the scanning Auger. Analysis on what appears to be an interface area could therefore include one or more of these voids and give erroneous results of the chemistry of a true interface.

On the void faces of Ni50Al, carbon was first found, then later replaced by sulfur [25]. As seen in Fig. 5, S on Ni50 Al voids was only observed after $100 \mathrm{hrs}$ at $1000^{\circ} \mathrm{C}$. The coverage on $\mathrm{Ni40Al}$ void faces, on the other hand, was much faster, even though the two types of alloys contain similar amounts of sulfur in the bulk (Table 1). Various levels of S were detected on different void faces. This variation was associated with different shapes of voids that were present on different alloy grains, which indicates some degree of orientation dependent $\mathrm{S}$ segregation on $\mathrm{NiAl}$ surfaces. Within the error bars, about three levels, 2, 5 and 7 at\%, were found on the void faces of Ni50Al. On Ni40Al, the levels ranged from 5, 7, 9-10 to 12 at\%; an AES spectrum from a 7 at\% void face on Ni40Al is given in Fig. 6(a). The 3\% found on the normal purity Ni40Al after only 10 min oxidation is likely the result of an unsaturated surface, where saturation is limited by the $\mathrm{S}$ concentration and its diffusion rate in the alloy. The S-doped $\mathrm{Ni}-40 \mathrm{Al}$, containing $>30$ ppm S, showed similar segregation behavior as the normal purity Ni-40Al that contains only a few ppm of $\mathrm{S}$, but saturation was reached much earlier, as expected.

The relationship between interfacial failure stress and interface sulfur concentration is shown in Fig. 7a. The failure strength was obtained by averaging 3-4 pull test results from a single sample, and this strength is plotted against the average sulfur content found on the same specimen, as determined by AES after scratching. Specimens were oxidized at $1000^{\circ} \mathrm{C}$ for times between $26-100 \mathrm{hrs}$ for the Ni50Al and 3-100 hrs for the Ni40Al. All samples had the same interface morphology of $\alpha-\mathrm{Al}_{2} \mathrm{O}_{3}$ imprints and occasional voids. The failure strength is seen to drop quickly with interface $S$ content, but only for the $\mathrm{Ni40Al}$ where $\mathrm{S}$ was detected. Ni50Al alloys that did not have any $\mathrm{S}$ at the interface also showed a range of failure strengths between $30-90 \mathrm{MPa}$. This scatter was not related to interface chemistry, such as the occasional presence of $\mathrm{P}$ and/or $\mathrm{B}$, even though $\mathrm{B}$ is known to strengthen alloy grain boundaries [27]. The fact that all S-free $\mathrm{Al}_{2} \mathrm{O}_{3} / \mathrm{Ni} 50 \mathrm{Al}$ interfaces failed at a range of strengths suggests that there were other factors contributing to scale 
adhesion. Interface porosity, which increased with oxidation time (as seen in Fig. 7b), and being crack-like defects, should be the most likely candidates.

Although the trend in Fig. 7a for Ni40Al indicates a strong interface weakening effect by the presence of sulfur, it should be noted that the variation in sulfur content was obtained from specimens oxidized at different times, so these samples have different scale thickness. Although the pull test results are not sensitive to film thickness, longer oxidation times can cause more defects in the scale and at the interface. Figure $7 \mathrm{~b}$ shows the interface porosity of each of the Ni40Al specimen whose sulfur content was presented in Fig. 7a. Specimens that had more sulfur at the interface also had greater interfacial porosity; both related to longer oxidation times.

Figure 8 compares the fracture strength as a function of interface pore density. In this plot, each strength data point was obtained from one pull stud. The number of pores at the exposed interface under that particular stud was calculated from several randomly taken SEM micrographs and plotted against the strength. To avoid different pore sizes from different oxidation conditions, all the data points were from specimens oxidized at $1000^{\circ} \mathrm{C}$ for 26 hours. Since the pore size on these alloys under a given oxidation condition was similar, the pore density can be used to give a good indication of the extent of defect concentration. The S-doped Ni40Al was not included, because all of its scale spalled upon cooling such that no pull tests could be performed. Results in Fig. 8 show a quick drop in interface strength with increasing pore density. However, the data seem to fit two different lines, with one (the dashed line) having a slower decreasing rate and a higher strength for a given pore density. This line runs through data points from Ni50Al whose interface was Sfree, but had a rougher, 240 grit $\mathrm{SiC}$ finished starting surface, i.e., those identified as

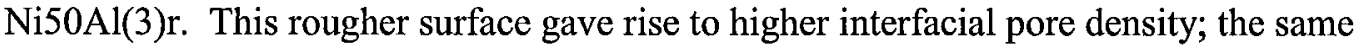
phenomenon had been observed on Fe40Al [24].

For all the normal $1 \mu \mathrm{m}$ diamond surface finish, the number of pores on $\mathrm{Ni40 \textrm {Al }}$ is seen to be higher than that on $\mathrm{Ni50Al}$, and this number could vary quite a bit even within one sample (see for example, the three data points from the Ni40Al(L) specimen). This shows that pore distribution is not uniform, similar to what was observed on Fe40Al [21]. The highest purity Ni50Al (batch 1) did not show interfacial failure after $26 \mathrm{hrs}$. That is why its data are not present on this figure. Quantification of pore developments on these alloys, which will be presented in a later paper [28], shows that the purity level of these alloys significantly influence interfacial pore formation. Pore formation is also related to the stoichiometry of the NiAl alloy, as previously reported by Blumm and Grabke [18].

When the fracture strength is compared with the interface pore area instead of the pore density (Fig. 9), the data became more scattered due to variations in pore size as well as density throughout the interface on every specimen. Figure 9 includes data from specimens oxidized at $1000^{\circ} \mathrm{C}$ after $26-100 \mathrm{hrs}$. The times were 50 and $65 \mathrm{hrs}$ for Ni50Al(1), 26 and $100 \mathrm{hrs}$ for Ni50Al(2), $50 \mathrm{hrs}$ for Ni50Al(3), $26 \mathrm{hrs}$ for Ni50Al(3)r, 26

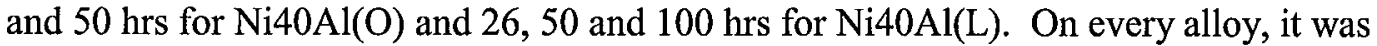
found that the pore fraction increased with longer oxidation time. Within the scatter, the beneficial effect of S-free interfaces of the Ni50Al alloy is still obvious (as indicated by the 
dash line). Under the same specimen surface finish, the $\mathrm{Ni40Al}$ alloys again developed greater total porosity than the Ni50Al alloys. Strength dropped very quickly with increasing pore fraction at the interface, then leveled off to a constant value. This level may no longer be dominated by the interface strength, but may be dictated by oxide fracture.

\section{DISCUSSIONS}

The segregation behavior at $\mathrm{Al}_{2} \mathrm{O}_{3} / \mathrm{Ni} 50 \mathrm{Al}$ and $\mathrm{Ni40Al}$ interfaces showed some interesting phenomena. First of all, $\mathrm{S}$ did not segregate to $\mathrm{Al}_{2} \mathrm{O}_{3} / \mathrm{Ni50Al}$ interfaces even after $265 \mathrm{hrs}$ at $1000^{\circ} \mathrm{C}$ or $100 \mathrm{hrs}$ at $1150^{\circ} \mathrm{C}$, when $\mathrm{S}$ already covered the void faces that were present at the interface. Of all the $\mathrm{Al}_{2} \mathrm{O}_{3}$-forming alloys studied by this method, i.e., AES after in-situ scratching [8], this is the first alloy where segregation to the interface did not occur. On the other hand, the slightly Ni-rich alloy, namely Ni40Al, which has the same phase and similar bulk impurity contents as the Ni50Al, forming an interface with the same type of oxide under the same oxidation conditions, consistently showed sulfur at its interface after a complete $\alpha-\mathrm{Al}_{2} \mathrm{O}_{3}$ developed, reaching a level of about 2 at\%. This behavior is similar to that previously observed on Fe-40Al [9].

Why should sulfur segregate to one $\mathrm{Al}_{2} \mathrm{O}_{3} / \mathrm{NiAl}$ interface but not the other, simply because of a difference in alloy composition? A possible explanation may lie in the relative stability of the two $\mathrm{Al}_{2} \mathrm{O}_{3} / \mathrm{NiAl}$ interfaces. It is known that the ordered $\mathrm{Ni} 50 \mathrm{Al}$ has a lower surface energy than Ni40Al [29]. Limited surface segregation study has shown that more S segregated to a Ni50Al single crystal surface when the surface was enriched with $\mathrm{Ni}$ from preferential sputtering of $\mathrm{Al}$ [30]. There is no prior information on the interface energy or the interface segregation behavior of the two alloys. However, indirect evidence from wetting studies of $\mathrm{NiAl}$ on sapphire shows that the $\mathrm{Al}_{2} \mathrm{O}_{3} / \mathrm{NiAl}$ interface energy decreases with increasing $\mathrm{Al}$ content in $\mathrm{NiAl}$ [31]. Theoretical analysis on metal/ceramic bonding have also shown that the interface energy between $\mathrm{Ni}(\mathrm{Al}) / \mathrm{Al}_{2} \mathrm{O}_{3}$ decreases with increasing $\mathrm{Al}$ activity near the alumina dissociation $\mathrm{P}_{\mathrm{O} 2}$ [32]. These studies suggest that the $\mathrm{Al}_{2} \mathrm{O}_{3} / \mathrm{Ni40Al}$ interface formed during oxidation would have a higher energy than that of the $\mathrm{Al}_{2} \mathrm{O}_{3} / \mathrm{Ni50Al}$. In that case, sulfur segregation should be more favored on the former to lower its energy.

The diffusion of S in Ni50Al must be significantly slower than in Ni40Al, since interfacial voids on Ni50Al were not covered with $S$ until after oxidation times greater than $100 \mathrm{hrs}$ at $1000^{\circ} \mathrm{C}$. Yet for the same amount of bulk S in Ni40Al (2-6 ppm), these void faces were covered with $\mathrm{S}$ as early as $0.5 \mathrm{hrs}$ at $1000^{\circ} \mathrm{C}$. Using the model of Lea and Seah [33], diffusion coefficients of $\mathrm{S}$ in the two alloys at $1000^{\circ} \mathrm{C}$ are calculated to be about $1.6 \times 10^{-7} \mathrm{~cm}^{2} / \mathrm{s}$ for $\mathrm{Ni} 40 \mathrm{Al}$ and $1 \times 10^{-9} \mathrm{~cm}^{2} / \mathrm{s}$ for NiAl. Diffusion of $\mathrm{Ni}$ in $\mathrm{NiAl}$ is known to be very sensitive to stoichiometry [34] due to strong variations of defect concentrations with composition. At $1300 \mathrm{~K}, \mathrm{D}_{\mathrm{Ni}}$ increases from $10^{-12}$ to $10^{-11} \mathrm{~cm}^{2} / \mathrm{s}$ from stoichiometric $\mathrm{NiAl}$ to Ni-40at\%Al. These values are $10^{3}$ to $10^{4}$ times lower than the $\mathrm{D}_{\mathrm{S}}$ calculated from the current segregation results, and the effect of composition on $\mathrm{S}$ diffusion seems to be stronger than that on $\mathrm{Ni}$. The $10^{3}-10^{4}$ difference in diffusivity between $\mathrm{S}$ and $\mathrm{Ni}$ agrees 
with recent data from $\mathrm{S}$ segregation studies on $\mathrm{Ni} 50 \mathrm{Al}$ surfaces [30], which determined that $\mathrm{S}$ diffusion in Ni50Al was about 3 orders of magnitude faster than $\mathrm{Ni}$ at $800^{\circ} \mathrm{C}$. On both alloys, the amount of segregated $\mathrm{S}$ was found to depend on void face orientation. Work is in progress to determine the orientation of different void faces using electron backscatter diffraction (EBSD), in order to correlate the segregation behavior to crystallography.

Considerably more voids were found on Ni40Al than Ni50Al, similar to results reported by Brumm and Grabke [18]. Nucleation of voids seems to be much easier on $\mathrm{Ni40Al}$ than on Ni50Al, giving rise to higher pore density at the interface. The greatest effect of excess sulfur in Ni40Al was to increase the number of interfacial voids. The void density after only $30 \mathrm{~min}$ at $1000^{\circ} \mathrm{C}$ was as high as $0.1 / \mu \mathrm{m}^{2}$, while the average number density on the regular purity $\mathrm{Ni40 \textrm {Al }}$ (from $5-100 \mathrm{hr}$ oxidation at $1000^{\circ} \mathrm{C}$ ) was only $0.01 / \mu \mathrm{m}^{2}$. Since the energy barrier for heterogeneous nucleation of a void is proportional to $(2+\cos \theta)(1-\cos \theta)^{4} \gamma_{m}^{3} / \Delta G_{v}^{3}$ [35], where $\Delta G_{v}$ is the volume free energy change of void nucleation, $\gamma_{\mathrm{m}}$ the surface energy of the metal and $\theta$ the angle between the pore edge and the oxide scale. Segregation of $S$ to the initial void embryo would reduce $\gamma_{m}$, and $\theta$ as well if the interface and oxide surface energies remain the same. This reduction of the nucleation energy barrier can explain why more voids formed on the S-doped Ni40Al, as similar effects were found on Fe40Al with impurity doping on the alloy surface prior to oxidation [24]. The same reasoning, however, cannot explain the difference in pore nucleation tendencies between the two NiAl alloys. Since $\gamma_{m}$ of Ni40Al is higher than that of Ni50Al [29], void nucleation should be harder for the former, but experimental results show the opposite. In this case, pore nucleation may be dominated by the higher number of point defects in Ni40Al [36] and/or their greater mobility [37].

The pull test used in this study is a technique that lacks a well-defined pre-crack so that failure depends on internal defects of unknown size and location. Stress concentration will also be higher at the stud edges, although this problem is alleviated by the spreading of some of the adhesive around the edge. The technique has the advantage that it is not as sensitive as other commonly used methods to the mechanical properties of the oxide or the alloy or to the scale thickness; it is also easy and has been used on many other scale/alloy systems [38]. When failures occur at the interface, the fracture strength gives an indication of the stress at which the scale is separated from the alloy. Defects that are present at the interface can act as crack initiators. Although the technique is inherently stochastic, a statistical analysis of the failure stresses directly correlated to interface defect concentration and chemistry can still be useful in providing a trend that shows relationships between failure and interface property.

The results of Figs. 7-9 show that $\mathrm{Al}_{2} \mathrm{O}_{3}$ scale adhesion on $\mathrm{NiAl}$ is related to the degree of interfacial porosity as well as the interface sulfur content. The dependence on porosity is not surprising, since the failure stress $\sigma$, is proportional to $K_{I C} / \sqrt{\pi c}$, where $K_{I C}$ is the interfacial fracture toughness and $c$ the critical defect size. Higher pore density and larger pore area fraction give rise to greater effective $c$. The more difficult question is the relative importance of defects and chemistry on interfacial strength. The fact that interfacial S and porosity both increase with oxidation time (Fig. 7b) makes it even harder 
to separate the two. However, by introducing more interface porosity through an initially rough polished surface, the strength of S-free and S-containing interface with similar pore density can be compared (Figs. 8,9). Although data scattering was large due to the random nature of pore formation, results show that under the same porosity, interfaces that contain sulfur was weaker. This could arise from a reduced interfacial toughness, where $\mathrm{S}$ at areas between pores weakens the interface to allow easier crack propagation.

Excess sulfur in Ni40Al greatly increased the number of interfacial pores, which is believed to be the reason why these scales were extremely non-adherent and spalled easily upon cooling. The amount of S segregated at the interface is probably not different from that found on the low sulfur Ni40Al. Although due to the presence of many sub microsized voids, conventional AES using a $0.5-1 \mu \mathrm{m}$ probe cannot clearly identify true interface areas, the amount of S segregated on large void surfaces did not vary with alloy $\mathrm{S}$ content. The same, therefore, is expected for the interface.

\section{CONCLUSIONS}

- Sulfur impurity in Ni50Al (2-5 ppm) did not segregate to $\mathrm{Al}_{2} \mathrm{O}_{3} / \mathrm{Ni50Al}$ interfaces where the scale was in contact with the alloy, but the same level in Ni40Al segregated after a complete $\alpha-\mathrm{Al}_{2} \mathrm{O}_{3}$ layer formed at the interface.

- Based on the rate of sulfur segregation to internal void surfaces, $\mathrm{S}$ diffusion in $\mathrm{Ni50 \textrm {Al }}$ and $\mathrm{Ni40 \textrm {Al }}$ at $1000^{\circ} \mathrm{C}$ was calculated to be approximately $1 \times 10^{-9}$ and $1.6 \times 10^{-7} \mathrm{~cm}^{2} / \mathrm{s}$ respectively. Segregation on void faces showed dependence on crystallographic orientation.

- Ni40Al had higher numbers of interfacial voids compared to Ni50Al. Doping the Ni40Al with excess sulfur significantly increased the interfacial void density.

- The fracture strength of these interfaces decreased with increasing interfacial porosity. Under the same degree of porosity, sulfur-free interfaces were stronger than S-containing ones.

- The role of sulfur on scale adhesion is two-fold: to enhance pore formation by lowering its nucleation energy, and to weaken the interface by accelerating crack propagation between pores.

\section{ACKNOWLEDGMENT}

The author would like to thank Dr. Bruce Pint of ORNL for supplying some of the alloys. This research is sponsored by the U. S. Department of Energy under contract No. DE-AC03-76SF00098.

\section{REFERENCES}


1. Y. Ikeda, K. Nii and K. Yoshihara, Trans. Japan Inst. Met. Suppl., 24, 207 (1983).

2. A. W. Funkenbusch, J. G. Smeggil, and N. S. Bornstein, Metall. Trans. A, 16A, 1164 (1985).

3. D. Lees, Oxid. Met., 27, 75 (1987).

4. J. L. Smialek, Metall. Trans. 22A, 739 (1991).

5. P. Y. Hou, Mater. and Corr., 51, 329 (2000).

6. P. Y. Hou, "Sulfur Segregation to Growing $\mathrm{Al}_{2} \mathrm{O}_{3} /$ alloy Interfaces", J. Mater. Sci. Lett., 19, 577-8 (2000).

7. P. Y. Hou, Mater. Sci. Forum, 369-372, 23 (2001).

8. P. Y. Hou, "Segregation Phenomena at Growing Alumina/Alloy Interfaces", J. Corr. Sci. Eng., 6, paper 75 (2003).

9. P. Y. Hou and John Moskito, "Sulfur Distribution on $\mathrm{Al}_{2} \mathrm{O}_{3} / \mathrm{FeAl}$ Interfaces Studied by Field Emission-Auger Electron Spectroscopy", Oxidation of Metals 59, 559-574 (2003).

10. R. Hutchings, M. H. Loretto and R. E. Smallman, Metal Science, 15, 7 (1981).

11. E. W. A. Young and J. H. W. de Wit, Solid State Ionics, 16, 39 (1985).

12. J. Doychak and M. Rühle, Oxid. Met., 31, 431 (1989).

13. B. A. Pint, J. R. Martin and L. W. Hobbs, Oxid. Metals, 39, 167 (1993).

14. M. W. Brumm and H. J. Grabke, Corr. Sci., 33, 1677 (1992).

15. R. Prescott, D. F. Mitchell and M. J. Graham, Corrosion, 50, 62 (1994).

16. E. Schumann J. C. Yang, M. J. Graham and M. Rühle, Mater. Corros., 46, 218 (1995).

17. J. C. Yang, K. Nadarzinski, E. Schumann and M. Rühle, Scripta Met, 33, 1043 (1995).

18. M. W. Brumm and H. J. Grabke, Corros. Sci., 34, 547 (1993).

19. J. L. Smialek, Met. Tran. A, 9A, 309 (1978).

20. H. M. Hindam, and W. W. Smeltzer, J. Electrochem. Soc., 127, 1630 (1980).

21. P. Y. Hou, Y. Niu and C. Van Lienden, Oxid. Met., 59, 41 (2003).

22. C. H. Xu, W. Gao and H. Gong, High Temp. Mater. and Proc., 19, 371 (2000).

23. H. J. Grabke, D. Wiemer and H. Viefhaus, Appl. Surf. Sci., 47, 243 (1991).

24. P. Y. Hou and C. Van Lienden, Mater. High Temp. 20, 357 (2003).

25. P. Y. Hou, "Chemical and Morphological Changes at $\mathrm{Al}_{2} \mathrm{O}_{3} / \mathrm{NiAl}$ Interfaces and Their Relationship to Scale Adhesion", in "High Temperature Corrosion and Materials Chemistry, $I V$," eds. E. Opila, P. Hou, T. Maruyama, B. Pieraggi, M. McNallan, D. Shifler, and E. Wuchina, the Electrochemical Society, PV 2003-16, pp. 40-50, 2003.

26. P. Y. Hou, in "High Temperature Corrosion and Materials Chemistry", ed. P. Y. Hou, M. J. McNallan, R. Oltra, E. J. Opila and D. A. Shores, pp. 198-210, the Electrochem. Soc., 1998.

27. C. T. Liu, E. H. Lee, E. P George and A. J. Duncan, "Intergranular fracture tendency in NiAl doped with boron and carbon," Scripta Met, 30, 387-92 (1994).

28. K. Priima and P. Y. Hou, "A comparison of pore formation at the interfaces between $\mathrm{Al}_{2} \mathrm{O}_{3}$ and $\mathrm{NiAl}, \mathrm{S}-$ doped NiAl, FeAl and NiPtAl," manuscript in preparation.

29. G. D. Ayushina, E. S. Levin, P. V. Del'd, Russ J. Phys. Chem. 43, 2756 (1969).

30. L. Rivoaland, V. Maurice, P. Josso, M.-P. Bacos and P. Marcus, "The effect of sulfur segregation on the adherence of the thermally-grown oxide on NiAl - I. sulfur segregation on the metallic surfaces of $\mathrm{NiAl}(001)$ single crystals and at $\mathrm{NiAl}(001) / \mathrm{Al}_{2} \mathrm{O}_{3}$ interfaces", Oxid. Metals, 60, 137-158 (2003).

31. E. Saiz, R. M. Cannon and A. P. Tomsia, "Reactive spreading: adsorption, ridging and compound formation," Acta mater., 48, 4449-4462, 2000.

32. W. Zhang, J. R. Smith and A. G. Evans, 'The connection between $a b$ initio calculations and interface adhesion measurements on metal/oxide systems: $\mathrm{Ni} / \mathrm{Al}_{2} \mathrm{O}_{3}$ and $\mathrm{Cu} / \mathrm{Al}_{2} \mathrm{O}_{3}{ }^{\prime}$, Acta Mater., 50, 3803-3816 (2002). 
33. C. Lea and M. P. Seah, Philo. Mag., 35, 213 (1977).

34. St. Frank, S. V. Divinski, U. Sodervall and Chr. Herzig, Acta mater., 49, 1399 (2001).

35. D. P. Woodruff, The Solid-Liquid Interface, Cambridge University Press, p. 21-38, 1973.

36. S. M. Kim, Y. Takeda and M. Kogachi, "Observation of high temperature Al vacancies and Al antistructure atoms in B2 NiAl alloys by in situ neutron diffraction", Scripta Materialia, 34, 1845-50, 1996.

37. Bai Bin, Fan Jiawen and G. S. Collins, "Vacancy mobility in nickel aluminide versus composition", in Diffusion Mechanisms in Crystalline Materials, ed. Y. Mishin, G. Vogl, N. Cowern, R. Catlow and D. Farkas, MRS Proceeding, pp.203-8, 1998, Mater. Research Soc., Warrendale, PA, USA.

38. P. Y. Hou and S. Saunders, "A Survey of Test Methods for Scale Adhesion Measurement," Workshop on scale growth and exfoliation in steam plant, Sept. 3-5, 2003, National Physical Laboratory, Teddington, UK, to be published in Mater. High Temp. 


\section{FIGURE CAPTIONS}

Figure 1: (a) Schematics of the pull test setup, (b) example of a failed area on Ni40Al after oxidation at $1000^{\circ} \mathrm{C}$ for $26 \mathrm{~h}$.

Figure 2: SEM image of a piece of scale from Ni40Al oxidized at $1000^{\circ} \mathrm{C}$ for $5 \mathrm{hrs}$ showing a two-layered morphology. The surface layer consists of needle shaped grains typical of the first-formed transition alumina. The underside contains a layer of $\alpha-\mathrm{Al}_{2} \mathrm{O}_{3}$ that nucleated later at the scale/alloy interface.

Figure 3: SEM micrographs of Ni40Al surfaces after scale removal. The alloy was oxidized at $1000^{\circ} \mathrm{C}$ for (a) $10 \mathrm{~min}$ and (b) $3 \mathrm{hrs}$.

Figure 4: Comparison of pore density on (a) normal purity Ni40Al, and (b) S-doped $\mathrm{Ni40Al}$ after oxidation at $1000^{\circ} \mathrm{C}$ for 30 minutes. The white color void faces have a layer of oxide film on them due to scale cracking and oxygen ingress during cooling.

Figure 5: The buildup of sulfur with oxidation time at $\mathrm{Al}_{2} \mathrm{O}_{3}$ /alloy interfaces and interfacial void surfaces of Ni40Al and Ni50Al. Specimens oxidized at $1150^{\circ} \mathrm{C}$ were plotted against times necessary to develop the same scale thickness at $1000^{\circ} \mathrm{C}$.

Figure 6: Typical AES spectra of void surface, Ni40Al and Ni50Al Interfaces. (a) Void surface on Ni40Al(L) after $26 \mathrm{hr}$, (b) interface of Ni40Al(L) after $26 \mathrm{hrs}$ and (c) interface of $\mathrm{Ni} 50 \mathrm{Al}(2)$ after $100 \mathrm{hrs}$.

Figure 7: Relationships between interface sulfur content and (a) interfacial fracture strength, and (b) interface porosity. Numbers next to data points represent the oxidation time in hours.

Figure 8: Relationship between interfacial failure stress and interface pore density. All

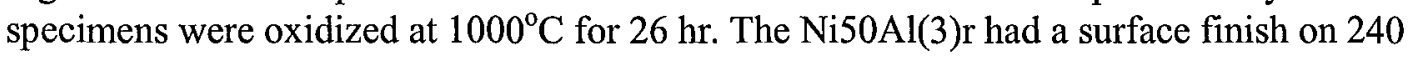
grit $\mathrm{SiC}$; all other specimens were finished on $1 \mu \mathrm{m}$ diamond.

Figure 9: Relationship between interfacial strength and interface pore area. Data include oxidation times ranging from $26-100 \mathrm{hrs}$ at $1000^{\circ} \mathrm{C}$. 
Table I: Compositions of the alloys determined by GDMS or ICP-OE analyses.

\begin{tabular}{|c|c|c||c|c|c|c|c|}
\hline \multirow{2}{*}{ Alloy } & \multicolumn{2}{|c||}{$\begin{array}{c}\text { Concentration } \\
\text { (at\%) }\end{array}$} & \multicolumn{6}{c|}{ Concentration (ppma) } \\
\cline { 2 - 8 } & $\mathbf{N i}$ & $\mathbf{A l}$ & $\mathbf{S}$ & $\mathbf{C}$ & $\mathbf{C l}$ & $\mathbf{P}$ & B \\
\hline $\mathrm{NiAl}(1)$ & 50.7 & 49.3 & $3.5^{*}$ & 320 & $<0.01^{*}$ & $2.8^{*}$ & $43.8^{*}$ \\
\hline $\mathrm{NiAl}(2)$ & 49.91 & 50.05 & $3.7^{*}$ & 360 & & & 40 \\
\hline $\mathrm{NiAl}(3)$ & 49.74 & 50.19 & $4.3^{*}$ & 710 & & & \\
\hline $\mathrm{Ni40Al}(\mathrm{O})$ & 59.7 & 40.3 & $6.6^{*}$ & 380 & & & 30 \\
\hline \hline $\mathrm{Ni40A1} \mathrm{(L)}$ & 60.1 & 39.8 & $2.2^{*}$ & 150 & & & \\
\hline $\mathrm{Ni}^{+}$-40Al (S-doped) & +60.9 & 40.0 & $34.7^{*}$ & 420 & & & \\
\hline
\end{tabular}

${ }^{+}$Alloys made at LBL. Others were made at ORNL.

*From GDMS (glow discharge mass spectroscopy) analysis, others were obtained using ICP-OE (inductively coupled plasma spectrometer-optical emission) analysis.

(a)

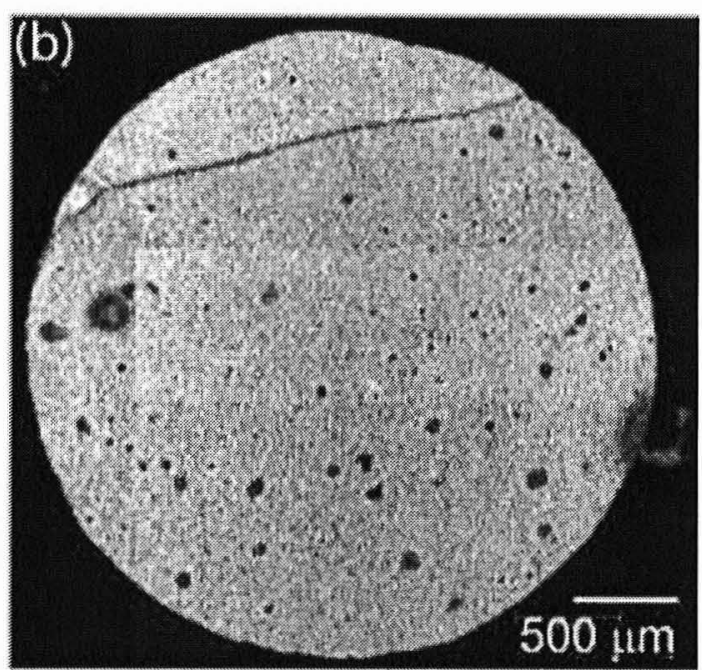

Figure 1:\{a) Schematics of the pull test setup, (b) example of a failed area on Ni4OAl after oxidation at $10000 \mathrm{C}$ for $26 \mathrm{~h}$. 


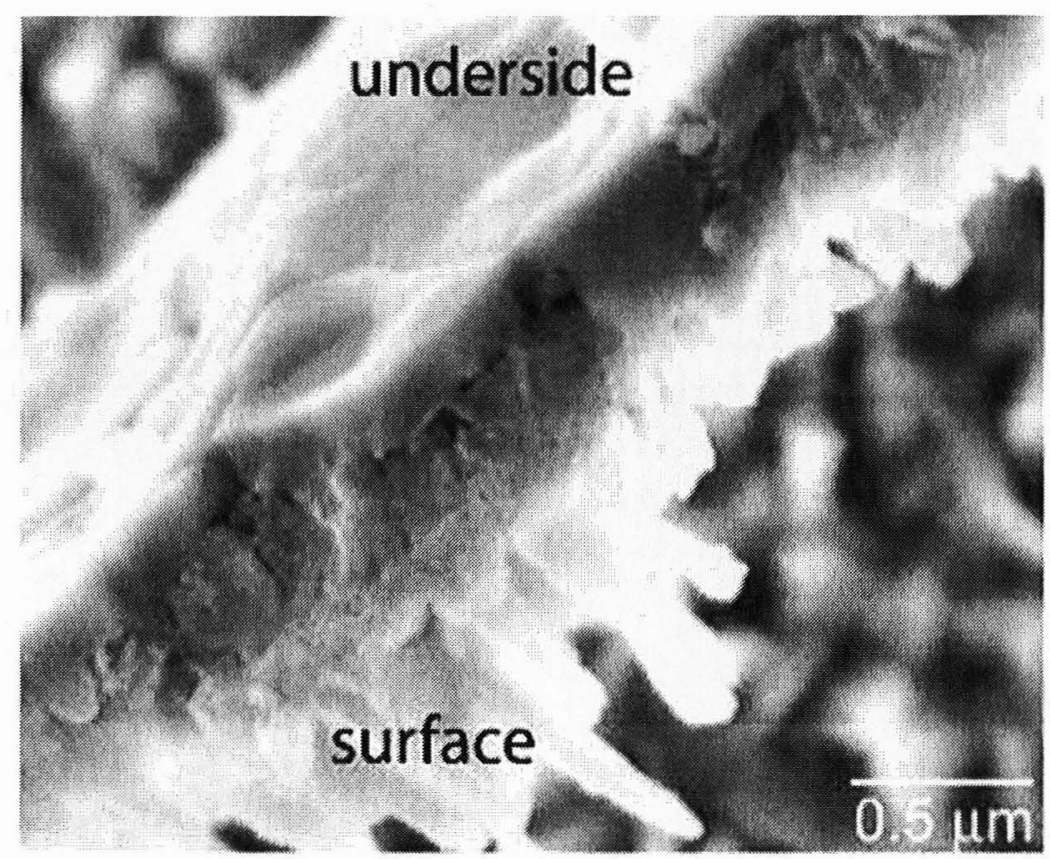

Figure 2: SEM image of a piece of scale from Ni40Al oxidized at $10000 \mathrm{C}$ for $5 \mathrm{hrs}$ showing a two layered morphology. The surface layer consists of needle shaped grains typical of the first-formed transition alumina. The underside contains a layer of -Al2O3 that nucleated later at the scale/alloy interface. 

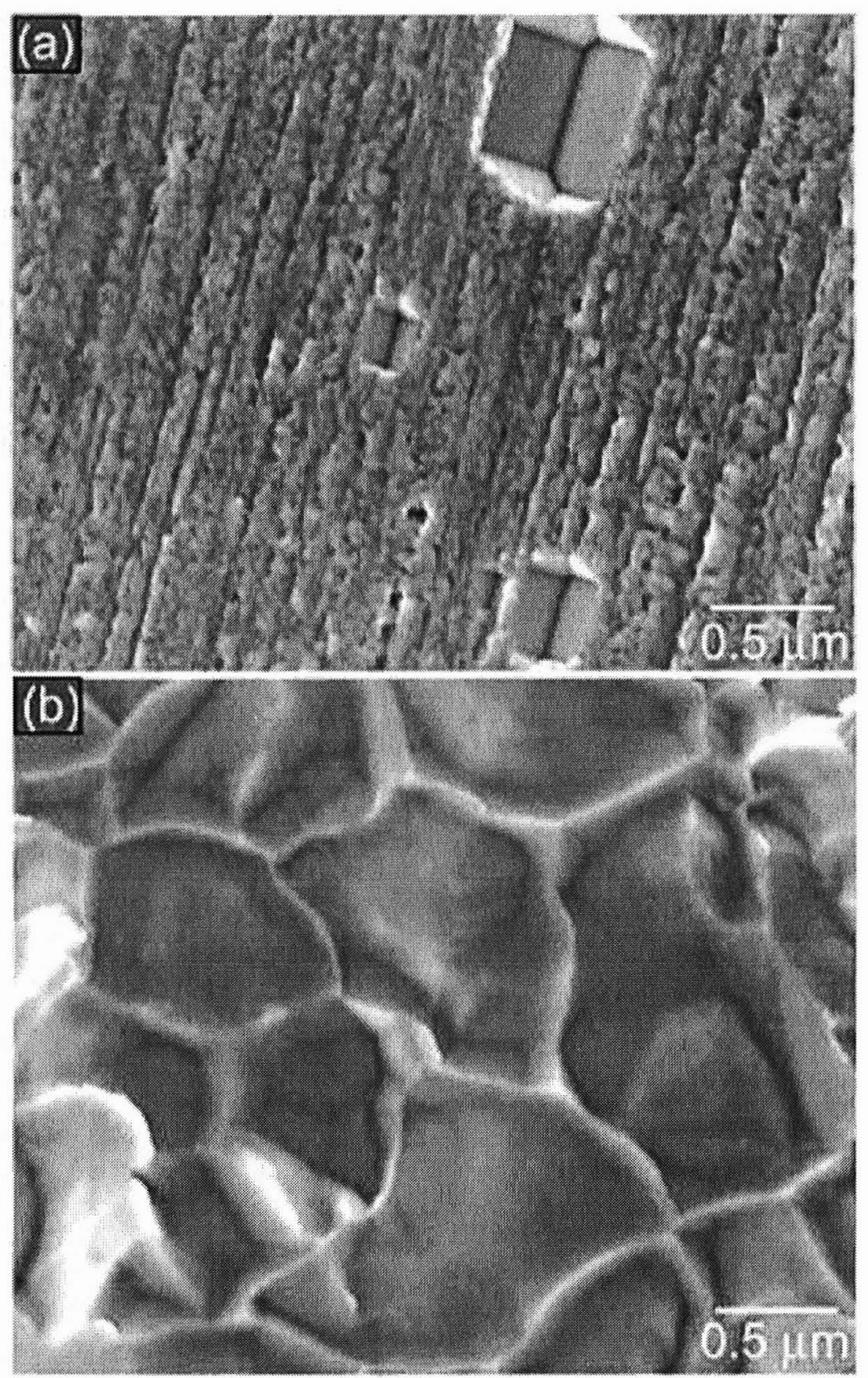

Figure 3: SEM micrographs of Ni40Al surfaces after scale removal. The alloy was oxidized at $10000 \mathrm{C}$ for (a) $10 \mathrm{~min}$ and (b) $3 \mathrm{hrs}$. 

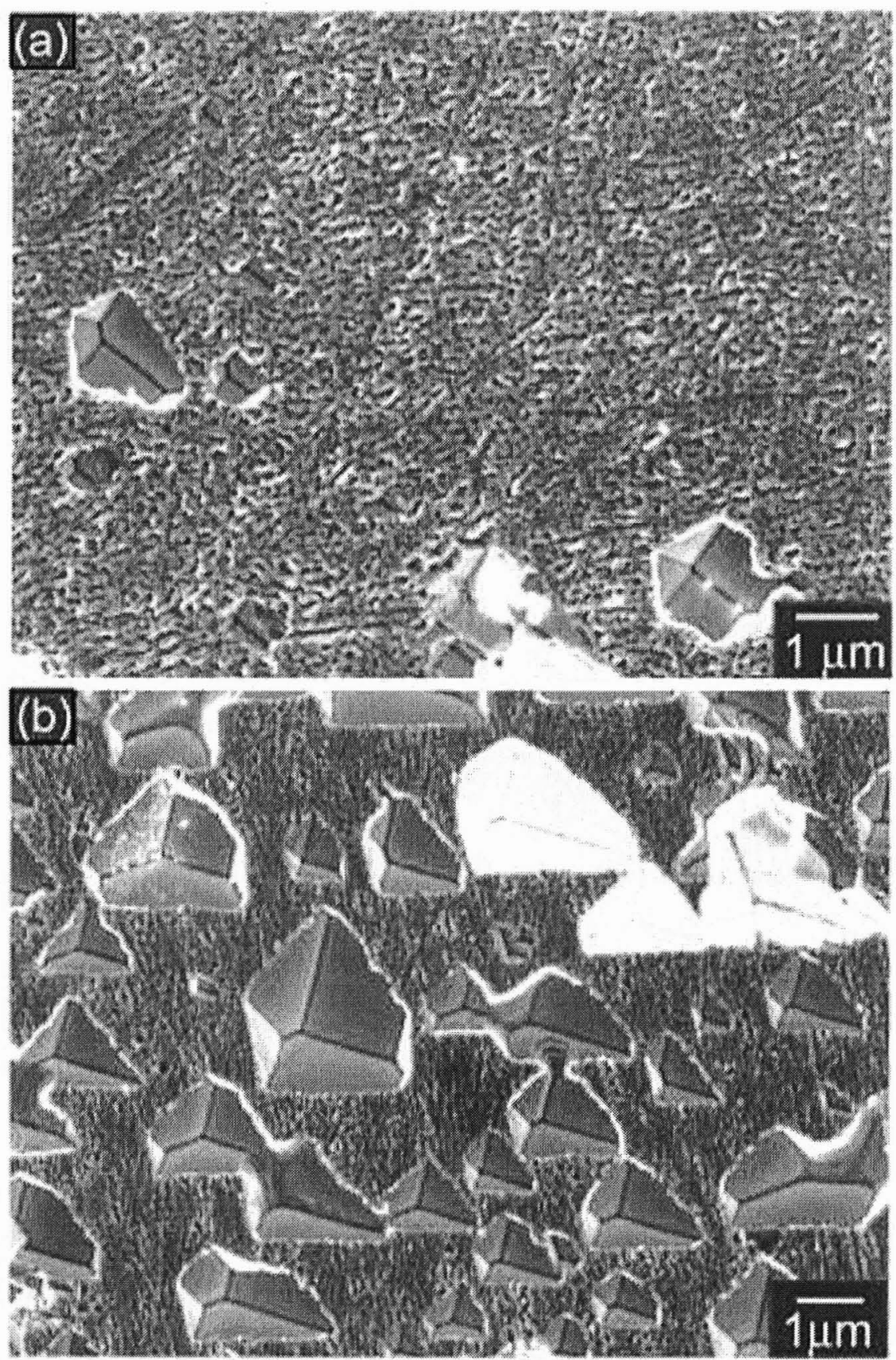

Figure 4: Comparison of pore density on (a) normal purity Ni40Al, and (b) 5-doped Ni40Al after oxidation at $10000 \mathrm{C}$ for 30 minutes. The white colar void laces have a layer of oxide film on them due to scale cracking and oxygen ingress during cooling. 


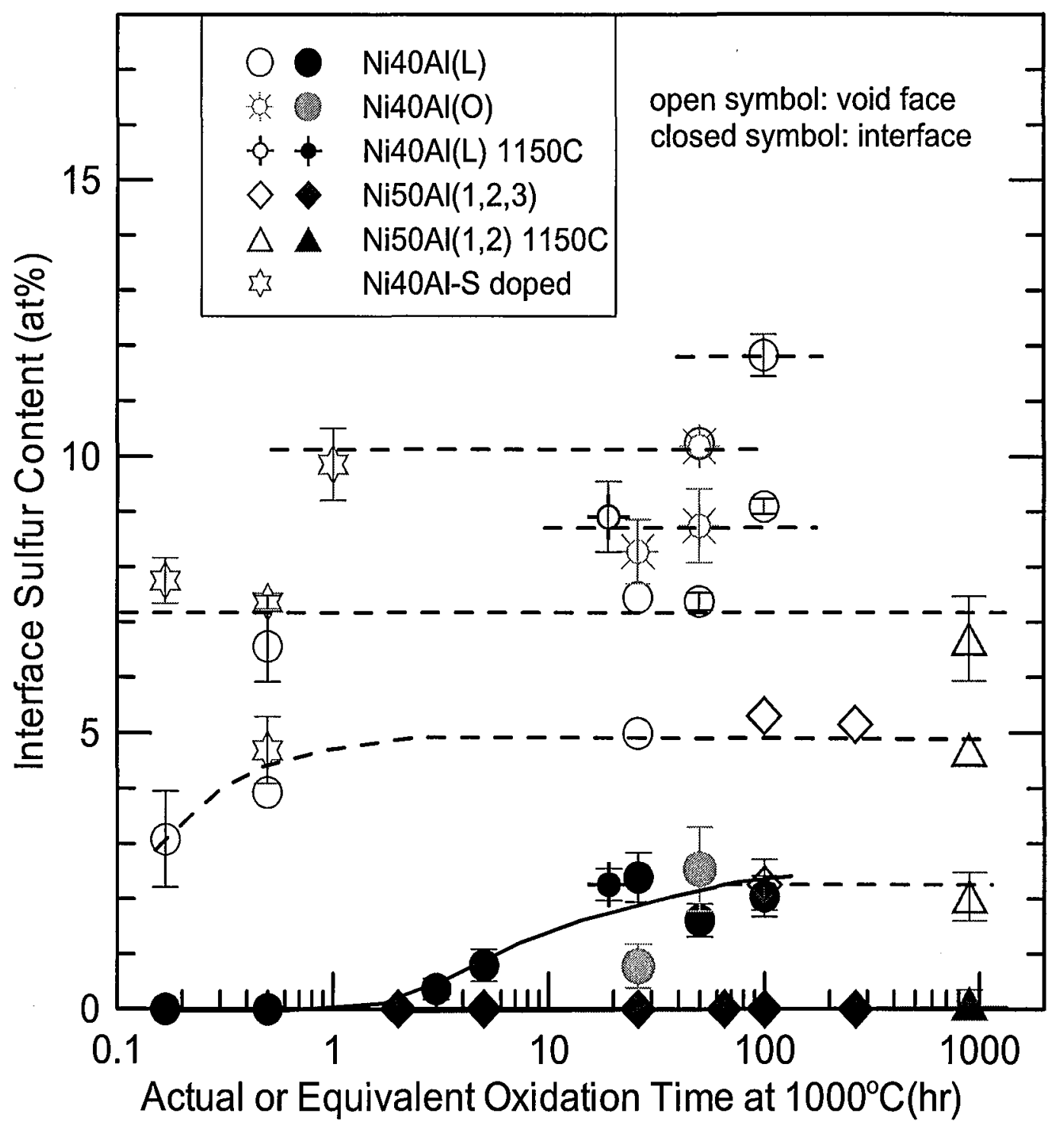

Figure 5: The buildup of sulfur with oxidation time at $\mathrm{Al}_{2} \mathrm{O}_{3}$ /alloy interfaces and interfacial void surfaces of Ni40Al and Ni50Al. Specimens oxidized at $11500 \mathrm{C}$ were plotted against times necessary to develop the same scale thickness at $1000^{\circ} \mathrm{C}$. 


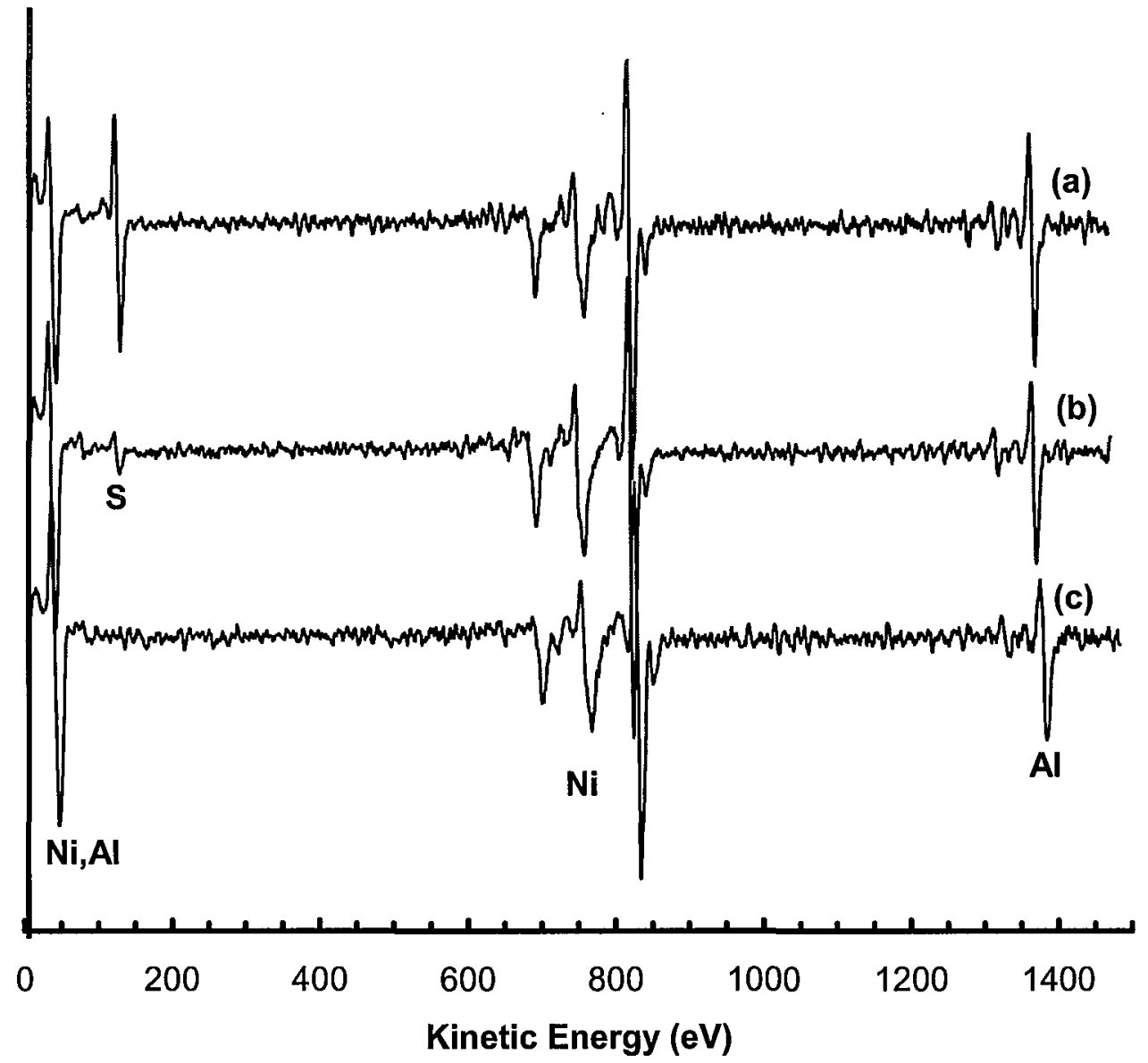

Figure 6: Typical AES spectra of void surface, Ni40Al and Ni50AI Interfaces. (a) Void surface on $\mathrm{Ni40Al}(\mathrm{L})$ after $26 \mathrm{hr}$, (b) interface of Ni40Al(L) after $26 \mathrm{hrs}$ and (c) interface of Ni50Al(2) after 100hrs. 
(a)

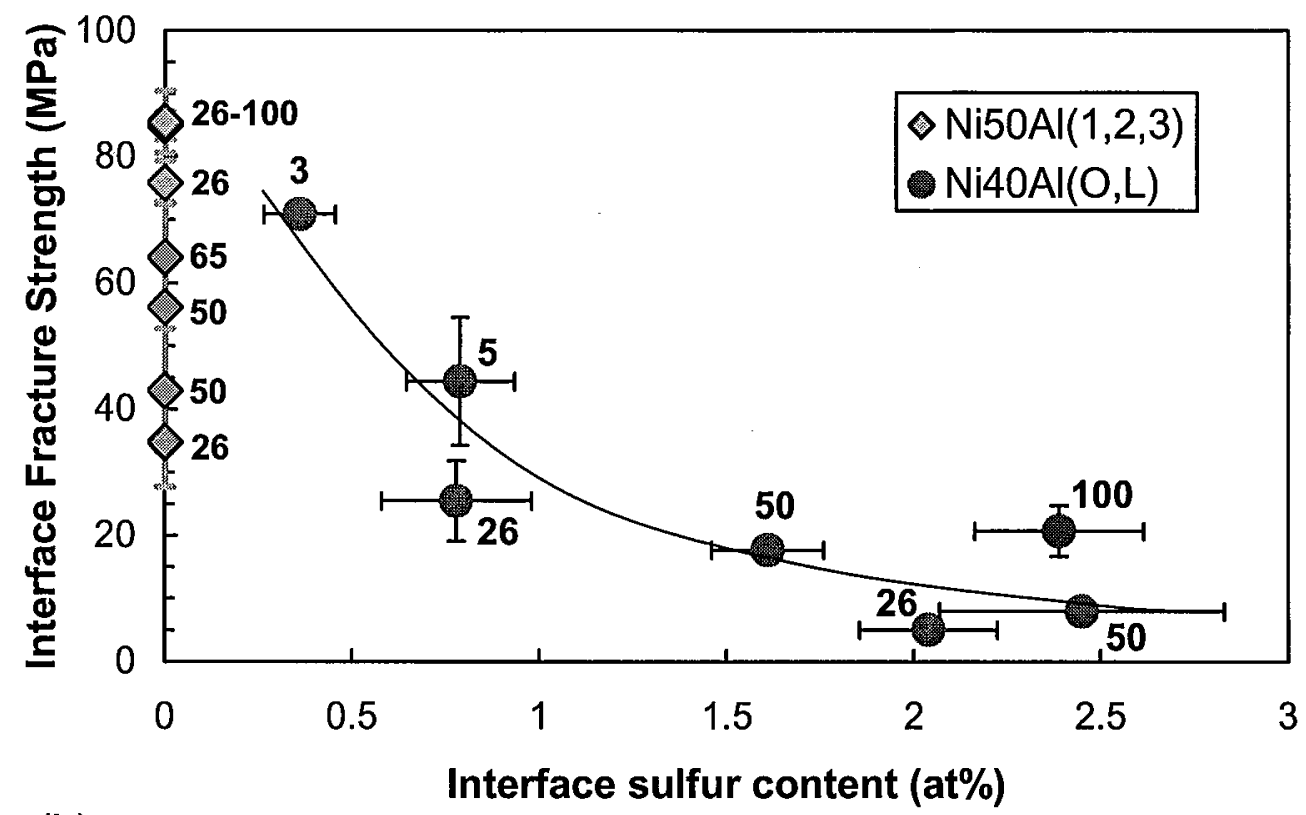

(b)

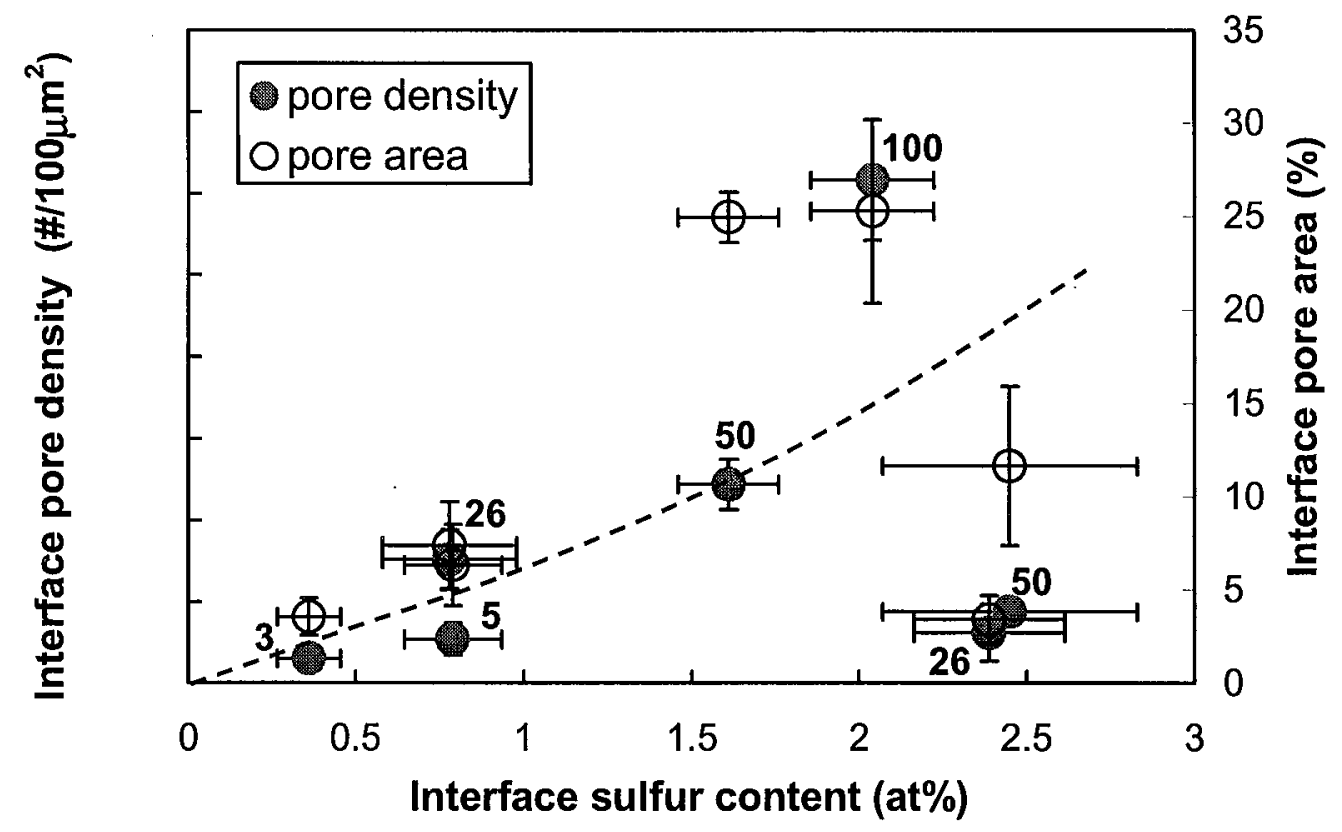

Figure 7: Relationships between interface sulfur content and (a) interfacial fracture strength, and (b) interface porosity. Numbers next to data points represent the oxidation time in hours. 


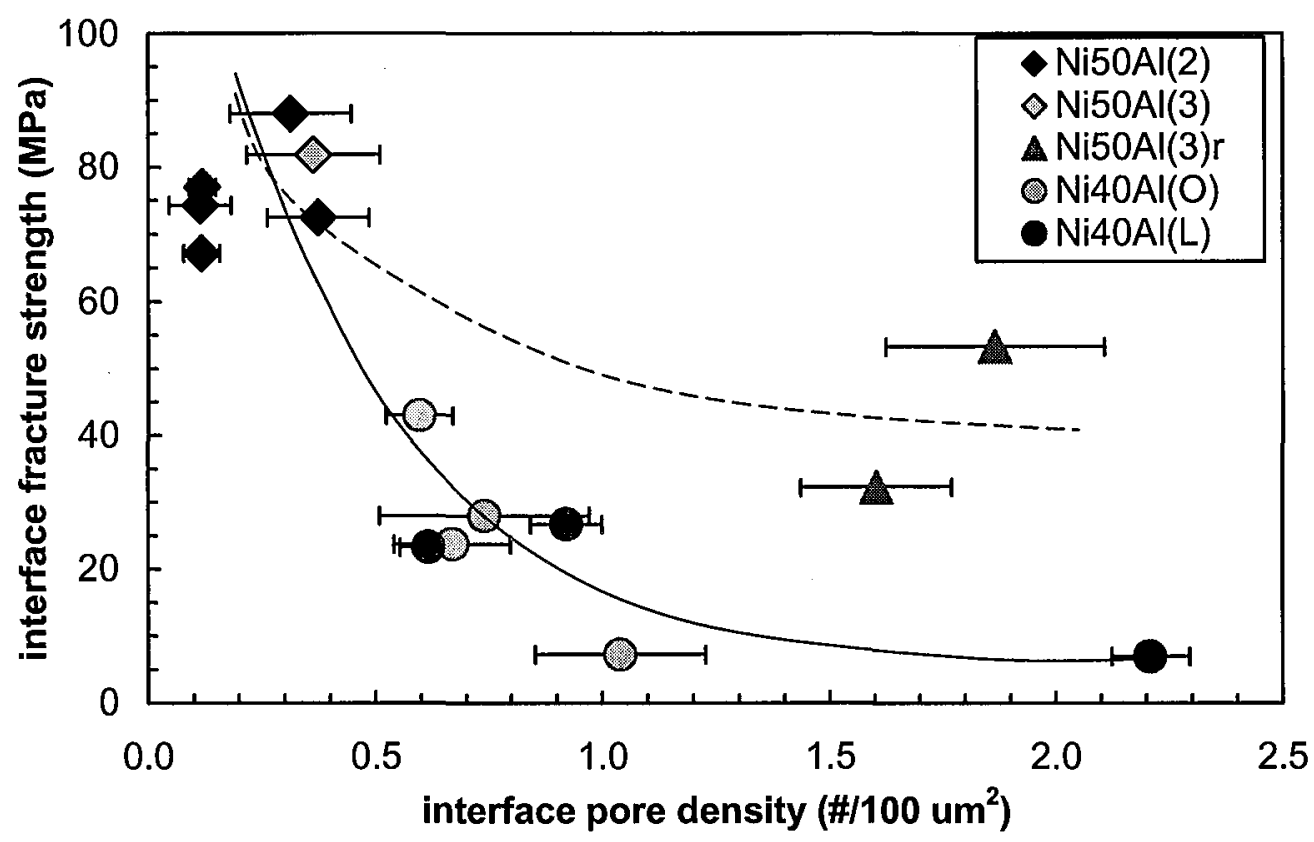

Figure 8: Relationship between interfacial failure stress and interface pore density. All specimens were oxidized at $1000^{\circ} \mathrm{C}$ for $26 \mathrm{hr}$. The Ni50Al(3)r had a surface finish on 240 girt SiC; all other specimens were finished on 1 $\mu \mathrm{m}$ diamond. 


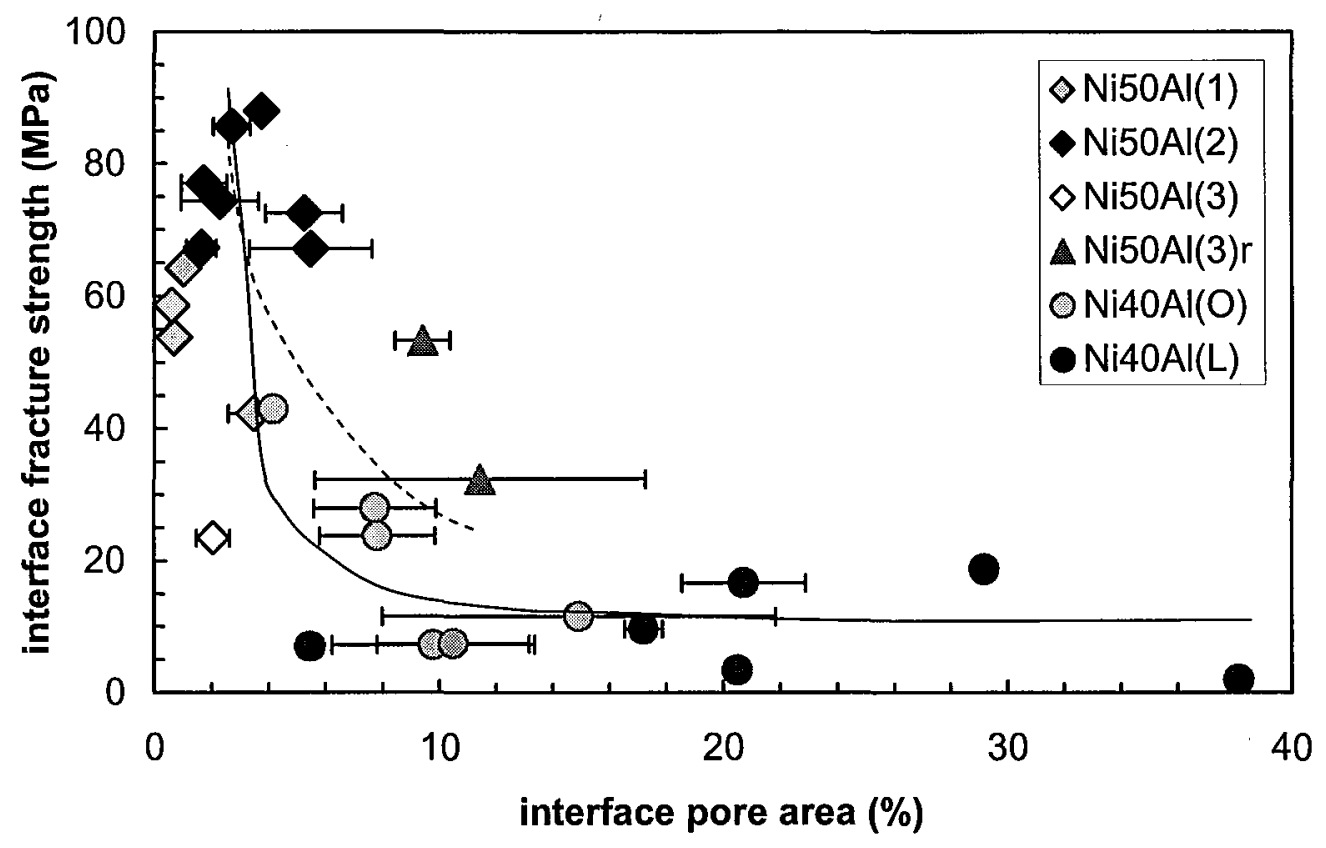

Figure 9: Relationship between interfacial strength and interface pore area. Data include oxidation times ranging from $26-100 \mathrm{hrs}$ at $1000^{\circ} \mathrm{C}$. 